\title{
An overview of the remaining challenges of the RILEM TC 274-TCE, testing and characterisation of earth-based building materials and elements
}

\author{
Antonin Fabbri ${ }^{1}$, Jean Claude More ${ }^{1 *}$, Jean-Emmanuel Aubert ${ }^{2}$, Quoc-Bao Bui ${ }^{3}$, Domenico Gallipoli ${ }^{4}$, Anne \\ Ventura $^{5}$, Venkatarama B.V. Reddy, Erwan Hamard ${ }^{5}$, Antoine Pelé-Peltier ${ }^{1}$, Holur Narayanaswamy \\ Abhilash $^{6}$
}

\footnotetext{
${ }^{1}$ Laboratoire de Tribologie et Dynamiques des Systèmes, UMR 5513 CNRS, ENTPE, University of Lyon, France

${ }^{2}$ LMDC, Université de Toulouse, INSA/UPS Génie Civil, 135 Avenue de Rangueil, 31077 Toulouse cedex 04, France

${ }^{3}$ Sustainable Developments in Civil Engineering Research Group, Faculty of Civil Engineering, Ton Duc Thang University, Ho Chi Minh City, Vietnam

${ }^{4}$ Dipartimento di Ingegneria Civile, Chimica e Ambientale, Università di Genova, Italy

${ }^{5}$ University Gustave Eiffel MAST/GPEM, Campus of Nantes, Route de Bouaye CS5004, FR-44344 cedex, France

${ }^{6}$ Indian Institute of Science, Bangalore 560012, India
}

Received: 26 July 2021 / Accepted: 14 December 2021 / Published online: 06 January 2022

(C) The Author(s) 2022. This article is published with open access and licensed under a Creative Commons Attribution 4.0 International License.

\begin{abstract}
Based on the RILEM Technical Committee 274-TCE work, this paper is a discussion of the remaining engineering challenges faced by earthen architecture. The assessment of earth material performances requires the development of appropriate procedures and standards. This is discussed in particular for the characterisation, hygrothermal behaviour, mechanical behaviour, and durability of earth materials. One other important challenge, since one of the main advantages classically put forward, is its ecological performance, is a proper assessment of life cycle assessment of earth materials, elements and buildings. Moreover, the paper develops why the approach to earthen construction must be different compared to the dominant construction materials, to preserve its ability to contribute to the ecological transition in the construction sector. In particular, the needs of using local soils, with an architectural approach coping with the limits of the materials, and developing an architectural optimisation to preserve the earthen materials multifunctionality rather than selecting a sole property to be maximised. Lastly, the findings of the paper can be used to develop a holistic approach to earthen construction to foster the development of new earthen architecture projects.
\end{abstract}

Keywords: Literature review; Earth construction; Earthen structures; Earthen architecture; STAR book; TCE 274; Testing procedures

\section{Introduction}

Earth is a building material excavated from the subsoil, which can be defined as an accumulation of parent material weathering products and biota degradation products. Earth is utilised by mankind since the Neolithic time all over the world. Wattle and Daub, Earth Plasters, Earth Mortars, Cob and then Adobe techniques were used in the Neolithic time. Rammed Earth appeared during the Iron Age, Compressed Earth Blocks (CEBs) and Light Earth emerged during the $20^{\text {th }}$ century. These techniques have spread from their territories of birth and have been adopted by other groups of people. When adopted, people get more and more familiar with the construction techniques and they adapt it to their natural environment and with their needs. These construction cultures are not immutable, they appear, evolve, expand and disappear, depending on the availability of resources and social changes. Earth built heritage reflects the outcome of this long evolution.

Various modern building techniques are used with earth, to build monolithic walls (cob, rammed earth), to produce bricks (adobe, CEB), as infill walls (wattle and daub) or as plasters or mortars (Figure 1). Earthen architecture had a rebirth since the last $6-7$ decades necessitated by the crunch on natural and energy resources and to provide better indoor comfort. Nonetheless, the earth building sector faces many challenges to be considered as a contemporary construction material. Earth construction will play an important role in the modern paradigm of sustainable buildings of the $21^{\text {st }}$ century if the stakeholders adopt earth construction processes able to meet social demand, with low environmental impact and at an affordable cost.

\footnotetext{
* Corresponding author: Jean Claude Morel, E-mail: jeanclaude.morel@entpe.fr
} 


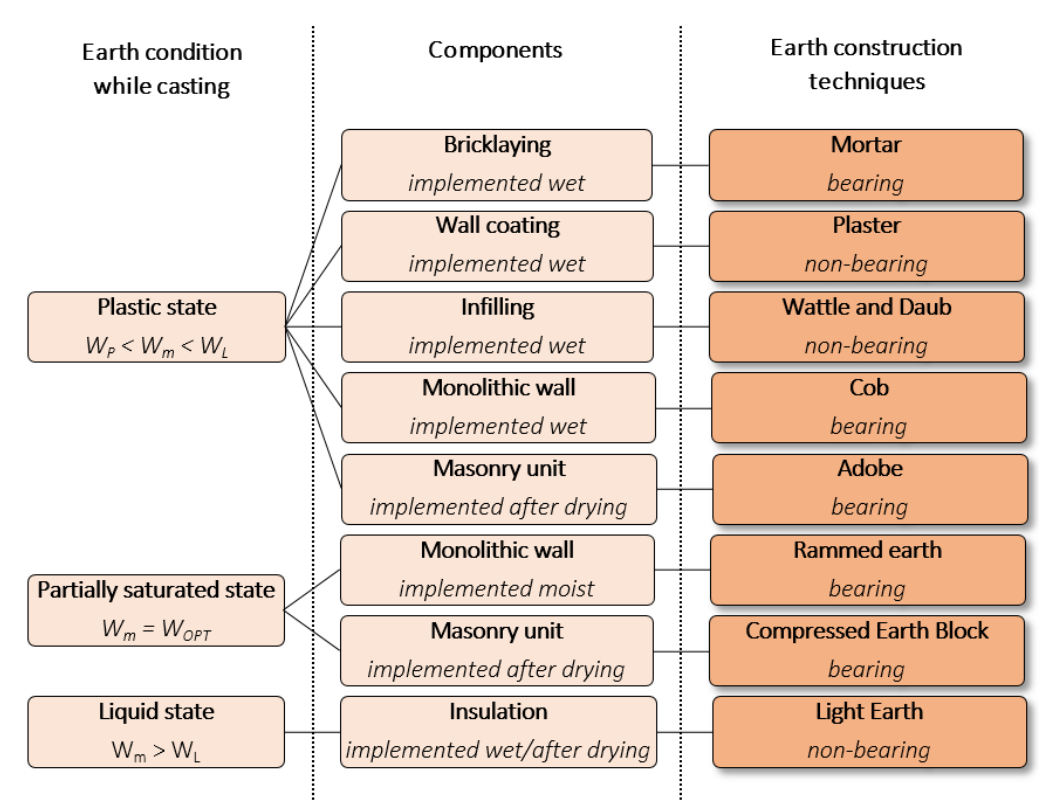

Figure 1. Earth construction processes classification, adapted after [1]. Where $W_{m}$ is the manufacturing water content, $W_{p}$ and $W_{L}$ the water content of Atterberg limits, respectively the plasticity index and liquid limit, and W

The first RILEM Technical Committee (TC) on earth as a construction material was the TC 164-EBM (1994-1999) focused on Compressed Earth Blocks (CEB). It was a milestone in the field notably with the development of procedures that are now integrated into some standards, [2], e.g XP P13-901 [3]. At that time, the international context would limit earthen architecture to low-income countries. Meanwhile, a very limited amount of scientific journal papers were published annually. Currently, earthen construction has gained momentum internationally among researchers including in high-income countries so that the second TC (274-TCE) on earth construction would include the variety of techniques described in Figure 1. The exponential growth of scientific publications on earthen architecture was noticed by some authors [4]. Naturally, an objective of the second TC was to summarize the state of the art in the field of materials and structures under the RILEM STAR book. Following this work, this paper is a discussion on the remaining challenges of the TC that can provide a perspective for future work to overcome the remaining obstacles against the development of earthen constructions, in the field of engineering.

\section{Characterisation}

Historically, the formulation and the manufacture of earth construction materials have been done empirically based on local traditional construction practices, often orally passed down from generation to generation by the builders who were also mostly farmers, who exploited earth for agriculture. Those builders learnt to adapt to the constraints of local materials and, in particular, to the properties of the local soils, without the need for scientific analysis and tools. The formulations used were the result of the experience gained at the construction site by the builders. But the sector of building materials and products has changed and today is based on standards, control, performance and modelling. In this logic, researchers are trying to rationalize the formulation of earth building materials or to understand and predict the behaviour of these materials through the characterization of raw materials.

Analysis of literature data shows that there are several characterization techniques in many fields: physics, geotechnics, chemistry and mineralogy. Deep knowledge of the characteristics of the raw materials is essential for optimizing the performance of earth materials but also for improving the understanding of the phenomena. The most measured property of the earthen materials is the particle size distribution. However, some studies show that it plays a role in the behaviour of earth materials, and is always not essential to get the grain size distribution of earth $[5,6]$. In addition to its ease of implementation, the use of this characteristic is often done to copy the approach adopted for industrially manufactured construction materials for whom the quality of the material is determined by its standard composition. But, this approach can be considered as a bias. This point is developed in the discussion section.

Actually, for all the properties studied in the TC, the most important is to know the nature and proportion of the active phase (namely the clay minerals that are the binder) of earth materials. For that purpose, the particle size distribution (which only gives the proportion of fines particles independently of their nature and whose denomination "clay" can lead to confusion) must, at a minimum, be completed by the measurement of geotechnical and chemical properties such as the Atterberg limits, the methylene blue value or the cation-exchange capacity [6]. The objective of these techniques is to assess the reactivity of the clays active phase, which depends on the type of clay and its proportion in the material. A thorough mineralogical characterization would allow measuring these parameters but this characterization is complex and still relatively rare in the studies found in the literature [7]. 
Finally, it was noticed that there is also an even more global scale of analysis: the field tests [8]. Field tests have the advantage of being easily performed, without significant costs. Therefore, results are obtained within a short period, which is very useful in the construction site. Nevertheless, they should be performed and results analysed by experienced professionals because they are mainly gathered by comparison. A perspective for future researches would be to assess scientifically the current field tests based on empiricism by developing appropriate models and lab experiments that would confirm their relevancy.

\section{Hygrothermal}

The characteristics of the indoor air are very important for the building's occupants because they can significantly influence comfort, health, and people's productivity. On the one hand, extremely low levels of relative humidity $(\mathrm{RH})$, below $30 \%$, may cause eye or skin irritations and dry the nasal mucous membranes, resulting in a higher risk of respiratory infections. On the other hand, high levels of $\mathrm{RH}$ may lead to the development of fungus, which can cause allergies as manifested by asthma and rhinitis $[9,10]$ and the emission of volatile organic compounds is favoured [11]. Also, it is important to emphasise that the development of biocontaminants (moulds, mites among others) is conditioned upon the level of $\mathrm{RH}$ : the capacity of earthen materials to limit bio-contaminants could be evaluated through the characterisation of its hygroscopic behaviour. In that context, the fact that due to their microstructure, earthen materials have commonly a good to excellent hygroscopicity (based on their Moisture Buffering Value $[12,13]$ is an asset that must be properly characterized. The main equations of hygrothermal couplings are nowadays quite well known by the scientific community (for example [14,15], and they can be summarized by the diagram of Figure 2 .

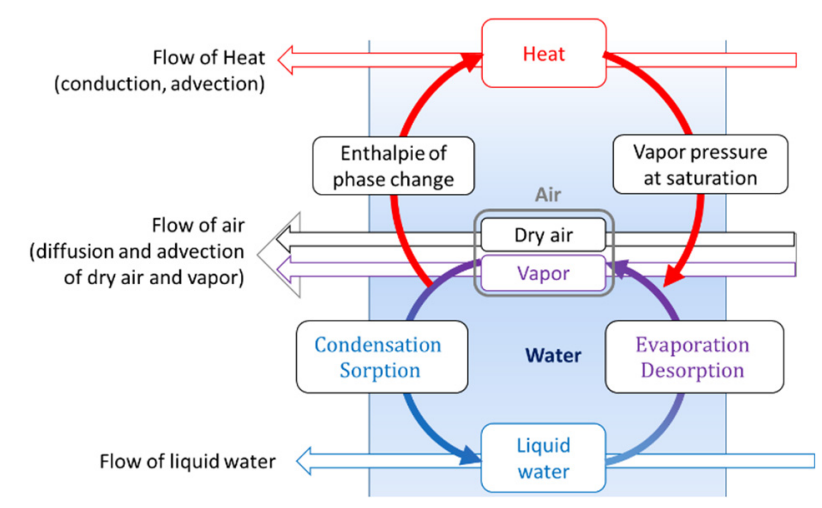

Figure 2. Diagram of heat and moisture transfers within an earthen wall.

The associate key parameters are the hydric storage capacity (or sorption/desorption isotherms), the vapour effective diffusivity (or $\mu$-value which is the ratio between the kinetic of diffusion of vapour in free air and within the material), the liquid water apparent permeability for mass balance equation plus thermal conductivity and heat capacity for the heat balance equation. In some particular configurations, it might also be necessary to know the air apparent permeability. However, one of the main current challenges is the proper determination of these parameters and their evolutions with temperature and water content. In particular, the work realised under the framework of the RILEM TC 274-TCE underlines the lack of a consensus on a procedure: to measure dry mass, while this latter is crucial for the determination of at least sorption-desorption capacity, dry density, thermal conductivity, and heat capacity. Similarly, different protocols currently coexist for almost all hygrothermal parameters (which is due to the lack of dedicated standardized procedures, see section 7), which complicates comparison between measurements. It follows that quite scattered values for these parameters can be observed in the scientific literature. For example, limiting ourselves to CEB of similar density, dry thermal conductivity between $0.2 \mathrm{~W} /(\mathrm{m} . \mathrm{K})$ and $1.6 \mathrm{~W} /(\mathrm{m} . \mathrm{K})$ can be found as well as $\mu$-values between 6 and 14. It is however difficult to know if this fact is due to real strong variations in earthen materials or to the difference in the experimental methods used to estimate these parameters (or both). On the other side, some consensuses are starting to emerge. It is now acknowledged that the measurement of vapour diffusion should consider the film moisture resistance at the sample surface $[16,17]$. Anyway, when they are submitted to performance tests like the Moisture Buffering Value tests, unstabilised earth materials commonly exhibit good to excellent hygroscopic properties.

Finally, it was found that the acoustical properties of earth building materials have been poorly studied and only a few references could be found, a similar conclusion was made by [18]. Hence, this is a field open to further research that should gain interest shortly.

\section{Mechanical behaviour and seismic resistance}

Unlike conventional construction materials, at present, the majority of the raw earth-based building materials do not have defined standard protocols or codes (see section 7.0). Therefore, the testing procedures for studying the behaviour of materials in compression, tension and shear were reviewed in the TC STAR book. The TC work itself was focused on the compression test procedures.

As there is a lack of established testing methodology for earth-based building materials, the standard testing procedures available for burnt clay bricks or concrete are generally adapted. Though, both these materials resemble similar functionality, the correction factors, specimen conditioning and correlations used for burnt bricks may not have similar relevance for earthen blocks [19]. This might be due to the differences in the intrinsic property of raw material, variability of soil mix, and manufacturing methodology. Most of the existing regional standards/documents for earth-based building material does not account for all the parameters. Therefore, while testing the significance of specimen conditioning, aspect ratio, specimen capping, rate of loading, specimen shape, size and orientation at test, shall be carefully examined and reported. Along with the classic testing procedures, new developments 
such as the RILEM test for earthen blocks and interface shear test for rammed earth has been introduced. One of the main challenges is the choice of the specimen to be tested. There is a conflict on the size that must be a few $\mathrm{cm}$ to be cheap and easy to test and the size closer to $50 \mathrm{~cm}$ to be representative of the in-situ material. For example, in the case of CEB is it relevant to test the block alone? Or isn't better to test a few blocks masoned together? The procedure with two half blocks stacked together with a mortar is chosen by the TC because it is certainly an optimisation of the size of the sample enabling an assessment of the masonry compressive strength with the same mortar. Strictly thinking the compressive strength is not of the CEB alone. It is very challenging to test the CEB directly with a lab press [20]. So that there is ground for new researches on that matter for CEB and extruded blocks. In the case of rammed earth where the biggest grains may have a diameter higher than $5 \mathrm{~cm}$, the size and weight of a representative sample may be more than $100 \mathrm{~kg}$, so that using smaller sample for lab test generate a scale effect that is still not well known. The lack of current data is on the modelling that would take into account appropriate labtested material parameters.

The seismic performance of a structure depends on the dynamic and static characteristics of the materials and the structure. The structure has a satisfying seismic behaviour when the intrinsic resistances of the structure and the materials are higher than the effects caused by the external actions (e.g. earthquake). The dynamic characteristics (natural frequencies, mode shapes, damping) are the key parameters to determine the seismic actions applied to the structure. Some of the static characteristics (Young's modulus, Poisson's ratio, density, structure geometry) influence the dynamic characteristics, others (such as compressive strength, tensile strength, shear strength) determine the performance of the structures under seismic excitations. It has been shown that the mechanical behaviour of earth materials is currently not linear elastic, and the mechanical strengths of earth materials are lower than that of conventional materials (concrete, steel). Moreover, the predominant natural frequencies of earth buildings are usually in the range in which the design seismic forces are high [21-23], which is not favourable for the seismic design of earth buildings. Therefore, to evaluate the seismic performance of earthen structures, advanced methods should be used. Indeed, the classical linear static analysis is not suitable; the non-linear static, response-spectrum modal and non-linear dynamic analyses are recommended [24-27]. One of the challenges of earthen structures in the seismic zones is the application of reinforcement techniques that satisfy different criteria: technical, economic and environmental. Although several seismic strengthening techniques have been discussed [28-34], further investigations on this topic are still necessary. In practice, the reinforcement techniques which are currently applied for conventional structures are also usually proposed by the engineers to apply for earth walls: the insertion of reinforced concrete beams and reinforced concrete columns; however, the significant difference in the stiffness between earth materials and the concrete may cause the damages during the dynamic excitations. The timber structures which have higher flexibilities than reinforced concrete or steel structures are suggested to be suitable for the reinforcement of earth buildings [35]. The wooden slabs - with the lightweight and the high flexibility which can dissipate the seismic energy - are recommended for earth buildings. Moreover, the association of earth and wood materials in a building is favourable for the hygrothermal behaviour and the passive design of the building. The reinforced concrete slabs are not recommended for earth buildings in the zones of high seismic risk, due to the high mass and the incompatibility of the stiffness. The quantitative evaluations on the relevancy of these different structural types are interesting for further investigations. The connection between the earth wall and the structural frame (timber/reinforced concrete/steel) is a complex topic that needs to be considered and improved. The behaviour factor of earth buildings is an important parameter in the seismic design (Eurocode 8-CEN 2004, [36]) which has not yet been investigated and presented in the literature. To determine the relevant behaviour factor, further studies, by experiments and numerical modelling, will be necessary.

\section{Durability}

The durability of earth buildings subjected to the action of water, ice, wind, fire, solar radiation and chemical agents depends on the degree of structural exposure and the relevant chemo-physical mechanisms. In general, liquid water appears the most detrimental of all the above environmental actions, not only because it reduces the capillary cohesion of the earth [37] but also because water can penetrate the material through multiple routes, e.g. rainfall, foundation rise, ambient humidity and utility leakage (Figure 3). Water can also be very damaging when present in solid form as the repeated expansion of pore ice, during freezing-thaw cycles, can produce spalling of earth structures. The threat posed by ice is highest immediately after construction when the earth is very moist, but it reduces with time becoming often negligible during service life when the water content equalizes at relatively low levels as proven by many vernacular structures. Some studies have also shown that freeze-thaw cycles can produce a localised hardening of the earth material [38].

Earth buildings are relatively resilient to wind as proven by the good state of many historical structures in windy regions of the world (Figure 4). Wind induces relatively minor damages, which can be regularly amended through the periodic maintenance of the building envelope [39]. Earth walls also exhibit good resistance to fire and their durability might even improve after exposure to high temperatures, in the same way as firing enhances the mechanical properties of clay bricks [40].

Solar radiation has normally a beneficial effect on the durability of earth buildings as it promotes evaporation of pore water with a consequent increase of capillary cohesion. Solar radiation may, however, undermine earth materials that have been stabilised employing organic binders, which are sensitive to photodegradation [41]. In this case, solar radiation can cause a range of damages going from a simple 
surface discolouration to more serious degradation of intergranular bonds. In general, earthen materials are chemically inert and the durability of unstabilised earth buildings is largely unaffected by chemical exposure, apart from the possible occurrence of localized cracking caused by the precipitation of salt crystals inside the pore water. Chemical degradation can instead be very severe in stabilised and steel-reinforced earth buildings due to the dissolution of intergranular bonds and/or the corrosion of rebars [42].

Currently, there are no international testing standards for measuring the durability of unstabilised earth materials, which is typically assessed in the laboratory according to different procedures in different parts of the world [43]. Moreover, distinct procedures have been developed to assess the impact of each environmental agent, which has contributed to the proliferation of experimental protocols and the consequent lack of a universally accepted measure of durability. Some of these protocols are complicated, timeconsuming and require equipment that is unavailable in conventional engineering laboratories. A possible way to overcome this disparity of experimental approaches may consist in differentiation between weathering protocols, which reproduce the effect of each environmental agent on the material, and durability protocols, which adopt a standardised procedure to measure a representative material property regardless of previous weathering history [4]. Relatively simple durability protocols may be chosen to maximise accessibility by practitioners and to facilitate acceptance as testing standards.

A very limited number of experimental studies have been undertaken to quantify the long-term durability of full-scale buildings exposed to weathering [44]. These studies have confirmed that stabilised earth exhibit lower erosion rates than unstabilised ones. Most importantly, they have shown that the cumulative erosion, measured over several years, is relatively small and may be deemed acceptable even for unstabilised earth structures if one takes into consideration the average service life of buildings.

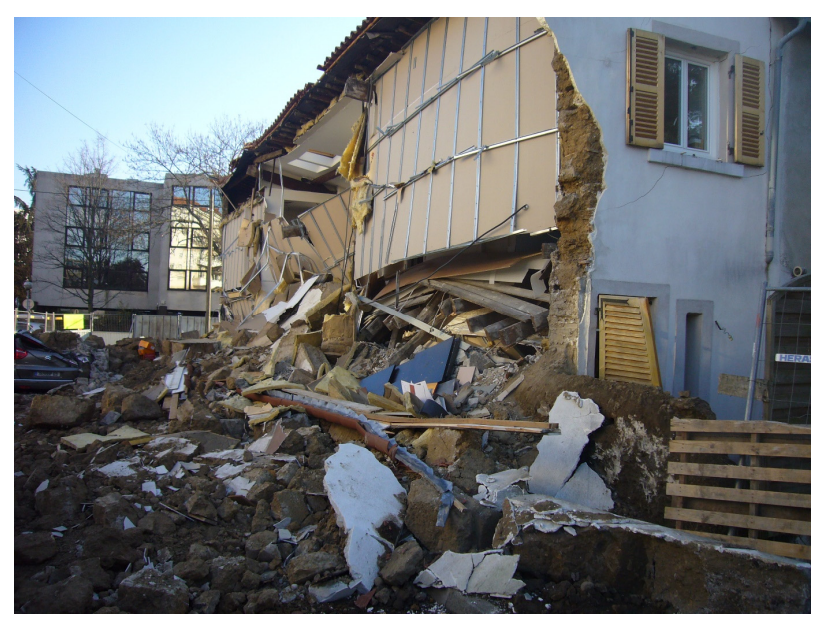

Figure 3. Structural collapse due to inappropriate refurbishment (cement bases, plaster, Rockwool insulation and gypsum board, among others) of a vernacular rammed earth house subjected to water accumulation at the wall base, Lyon, France.

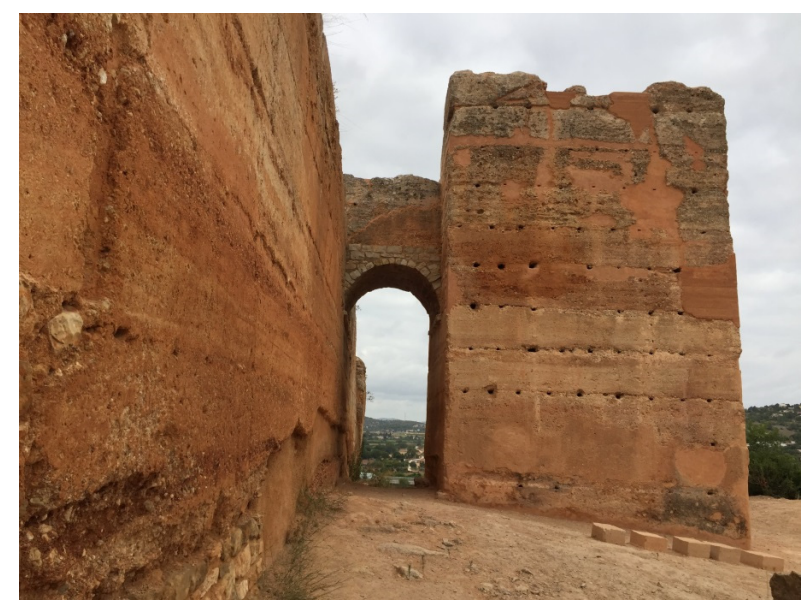

Figure 4. Paderne Castle (12th century) in Algarve, Portugal.

\section{Codes and standards on earth construction}

Any engineered construction demands guidelines for the production of materials, construction of the structural elements, thermal comfort and durability of the structures/buildings. Even though earth construction exists since the dawn of civilisation, there is a lack of universally accepted standardisation on the material production and construction methods as compared to the standards available on conventional materials such as concrete, masonry, steel, etc. There are attempts in the recent past to develop codes of practice and normative standards for modern earth construction, which can facilitate the building professional to design and construct modern earth buildings. The specifications and information on the earth construction in these regional and national standards differ widely and do not cover all the techniques or all the technical features of the material. There is a need to take stock of the existing information on the earth construction standards and propose comprehensive and universally applicable ones. For developing global standards on earth construction, there is a need for the common terminology for different types of earth construction techniques and earthen materials, as it is currently lacking [45]. Appropriate international standards for lab testing are then required. Both to homogenize the scientific data, gathered on the material, at an international scale but also to provide the quality control and the verifications necessary in a performance-based approach, [46].

For example, for the structural design of rammed earth, compression tests are particularly important, as one of the most significant parameters, for structural designers, is the compressive strength, [47], see section 4 . In that case, the inaccuracy of existing codes can also be a problem. In particular, the safety factor considered is generally too high, 3 to 8 in the MOPT (1992) [48] in Spain for rammed earth for example, and then can lead to an underestimation of the load-bearing capacity of earth walls, which cause a low economic efficiency, [49]. Moreover, building codes sometimes have compressive strength specification values that are unreachable without stabilization [50], increasing the environmental impact of the material. Hence, without the support of regulatory institutions, which sometimes do not 
want to take responsibility, building designers usually have to create their own method for each building, leading to a complex approval process. Besides discouraging designers, this can also create additional costs [51].

\section{Environmental potential of earth-based building materials: Key facts and issues from a Life Cycle Assessment perspective}

Current earth construction, derived from ancestral vernacular techniques, is being rethought to be better adapted to today's technical and economic constraints. It is possible to simplify the approaches in two schools of thought. The first is to use unstabilised earth, playing on the architecture to achieve a relevant building. The second tendency, criticised by [52] is to use stabilizers, mainly cement and lime, to increase strength and water stability [53-55]. However, these evolutions generate environmental impacts that have to be investigated using Life Cycle Assessment (LCA). Existing literature performed on the LCAs or life cycle approaches applied to various earthen construction techniques have been examined, to seek key factors improving their environmental impacts. As the different articles use different methods to calculate impact indicators, the comparisons only focus on Cumulative Energy Demand (CED). Transports, as well as stabilizers, are found very influential on CED. Climate, nature of local soil, and geographical context are very influential on functionalities of buildings, mix design and transports, themselves influencing CED.

According to design choices detailed above as well as local context and expected usage, earthen constructions are not always better than concrete constructions, especially if the expected usage requires high mechanical performances [52]. All references comparing walls material to conventional materials at the building scale, find better environmental performances of earthen walls compared to fired brick walls. However, a full comparison between earthen construction and conventional materials should also account for the use phase: combining LCA models with thermal and durability models is a key research issue. Furthermore, the choice of material is far from being the only issue in LCA of buildings, no universal solution can be recommended without specifying expected usage conditions and their implementations in the form of functional performances in a local context.

It certainly would be useful to seek solutions with the best environmental performances in a local context, accounting for the nature of the soil, the building's functional requirements as well as geographical and cultural specificities. Such an approach would ensure lower environmental impacts but represents a drastic change in current construction practices. Whereas today building materials are standardized to fit with construction working practices, this paradigm shift would require adapting construction working practices to the local material and context. As earthen construction is today, in many countries of the world, a re-emerging technique, and new professional practices are yet to be established, it seems possible to make this paradigm shift happen. This requires the development of numerical tools able to provide optimised environmental solutions according to specific local constraints such as availability and characteristics of local material, usable techniques, or climate. Certainly, in the current context of the need to substantially reduce building-related greenhouse gas emissions, there is still strong potential in earth construction techniques for both research and building practice.

\section{Discussion and perspectives for future work}

The last two decades have seen an exponential growth of peer-reviewed papers on earthen architecture. In this context, the RILEM Technical Committee 274-TCE has completed one of its objectives which was to elaborate a literature review, the state of the art on testing and characterisation of earth-based building materials and elements (STAR book framework of the RILEM). By assembling the state of the art on earth construction in the field of materials and structures, the aim was to facilitate the share of knowledge and foster the construction of modern earthen architecture and the proper refurbishment of existing assets. This work shows that there is already a relevant amount of knowledge in the field, however, in practice earthen constructions are still a niche market. That said, some authors have shown that the barriers against the development of earthen constructions are not only technical but also social, organizational, political and economic, whereas the scientific literature is mostly limited to technical challenges [56]. There would be ground for clarification on that matter, notably concerning the interrelation of the technical barriers and the architecture and management of projects in the context of circular economy $[57,58]$. This is crucial to achieving the aim of the ecological transition in the field of the built environment for low rise buildings. In particular, the earth constructions have the potential to be excellent in frameworks like the circular economy [56], the 18 nature contributions to people, and the 17 UN sustainable development goals [59]. Those frameworks should be used to engage the construction sector in a true ecological transition and to stop greenwashing.

From the engineering point of view, the challenges of the R\&D on earthen buildings are different from the classical challenges of industrialised materials because the optimisation of earthen materials is to preserve its multifunctionality rather than selecting a sole property to be optimised. The still open challenges are the need for the preservation of the variety of earthen materials, techniques and architecture because it is a means to minimize the impact on the environment and secure a possible optimisation of the constructions. Prioritising the use of local soils (in unstabilised earth construction) is key and that is why there are varieties of earth compositions used as construction materials. So that we should always prioritise the material multi-performance against the material composition.

The establishment of comprehensive regulations and codes for earth material is an absolute necessity both to help designers and to develop the field of earthen construction, [60]. 
The new global standards should address the following generic items:

1. Earth selection, composition/grading

2. Moulds and machinery

3. Production or manufacturing techniques

4. Testing \& quality control

5. Structural design guidance including earthquake resistance design

6. Construction methodology and construction procedure

7. Thermal performance, hygroscopicity and moisture buffering

8. Durability, maintenance and limitations

Although a basic application of codes designed for other materials is irrelevant, it may be also possible to rely on existing codes not specifically dedicated to earthen materials. In Europe, for example, the Eurocodes, based on a semiprobabilistic design concept are commonly used by designers [49]. The Eurocode 0, which describes the basis of the structural design, is supposed to give guidelines for the design of all types of materials. Thus, before creating a specific code for earth material, the assessment of the possibility to design earth building by using Eurocode 0 could also be investigated.

Although the sharp increase in scientific publications, the amount of data and knowledge on earth is still limited in all fields and far less than the industrial materials like concrete, steel or even baked bricks among others. Due to the urgency of the agendas of the mitigations of the key societal challenges like global warming, biodiversity collapse, shortage of decent dwelling for million people, obstacles against a truly circular economy, it seems to us preferable to focus the studies on appropriate testing procedures, modelling, reduction of the cost of the manufacture, to support a straight transfer to the field, rather than trying to improve the material performances with new additives that would increase the negative impacts on the environment without assurance of reaching the excellence of engineering properties of industrial materials that have been already optimised for decades.

\section{Acknowledgement}

This work was realized in the framework of the RILEM Technical Committee TCE 274. The authors would like to acknowledge all the active members of this TC. We wish to cite the contributors to the TC: Chris Beckett, Ana Bras, Agostino Walter Bruno, Paulina Faria, Guillaume Habert, Rogiros Illampas, Ionnis Ioannou, Emmanuel Keita, Thibaut Lecompte, Pascal Maillard, Fionn Mcgregor, Daniel Oliveira, Claudiane Ouellet-Plamondon, Celine Perlot, Noémie Prime, Damien Rangeard, Abbie Romano, Rui Silva, Humberto Varum.

\section{Authorship statement (Credit)}

Fabbri A. and Morel J.C.: Writing - original draft, Writing review and editing; Conceptualization; Project administration.
Aubert J.E., Bui Q.B., Gallipoli D., Ventura A., Reddy B.V.V.: Writing - original draft, Writing - review and editing; Project administration.

Hamard, E. Pelé-Peltier A. and Abhilash H.N.: Writing original draft, Writing - review and editing.

\section{References}

[1] E. Hamard, Rediscovering of vernacular adaptive construction strategies for sustainable modern building - Application to Cob and Rammed Earth. ENTPE. (2017) Available at: http://www.theses.fr/2017LYSET011

[2] M. Olivier, A. Mesbah, Z. El Gharbi, J.-C. Morel, Mode opératoire pour la réalisation d'essais de résistance sur blocs de terre comprimée. Mat Struct (1997) 30: 515-517. https://doi.org/10.1007/BF02486394

[3] AFNOR, XP P13-901 Briques et blocs de terre crue pour murs et cloisons - Spécifications et méthodes d'essai.

[4] C.T.S. Beckett, P.A. Jaquin, J.-C. Morel, Weathering the storm: A framework to assess the resistance of earthen structures to water damage. Constr Build Mater (2020) 242. https://doi.org/10.1016/j.conbuildmat.2020.118098

[5] J.-E. Aubert, A. Marcom, P. Oliva, P. Segui, Chequered earth construction in south-western France, Journal of Cultural Heritage. J Cult Herit (2015) 16 (3) : 293-298. https://doi.org/10.1016/i.culher.2014.07.002

[6] F. Rojat, E. Hamard, A. Fabbri, B. Carnus, F. McGregor, Towards an easy decision tool to assess soil suitability for earth building. Constr Build Mater (2020) 257. https://doi.org/10.1016/i.conbuildmat.2020.119544

[7] K.A.J. Ouedraogo, J.-E. Aubert, C. Tribout, G. Escadeillas, Is stabilization of earth bricks using low cement or lime contents relevant? Constr Build Mater (2020) 236. https://doi.org/10.1016/i.conbuildmat.2019.117578

[8] Neves, C., Faria, O., Rotondaro, R., Cevallos, P.S., Hoffmann, M. (2010) 'Seleção de solos e métodos de controle na construção com terra práticas de campo'. Rede Ibero-americana PROTERRA. Available http://www.redproterra.org

[9] A. Arundel, E. Sterling, J. Biggin, Indirect health effect of relative humidity in indoor environments. Environ Health Perspect (1986) 65: 351. https://doi.org/10.2307/3430203

[10] H. Gonçalves, B. Gonçalves, L. Silva, N. Vieira, F. Raupp-Pereira, L. Senff, J.A. Labrincha, The influence of porogene additives on the properties of mortars used to control the ambient moisture. Energy Build (2014), 74: 61-68. https://doi.org/10.1016/j.enbuild.2014.01.016

[11] L. Fang, G. Clausen, P.O. Fanger, Impact of temperature and humidity on chemical and sensory emissions from building materials. Indoor Air (1999) 9: 193-201. https://doi.org/10.1111/j.1600-0668.1999.t01-1-00006.x

[12] P. Faria, A. Bras, Performance of Bio-based Building Materials. Building Physics, D. Jones, C. Brischke (Eds), 2017

[13] F. McGregor, A. Heath, D. Maskell, A. Fabbri, J.-C. Morel, A review on the buffering capacity of earth building materials, Proceedings of the Institution of Civil Engineers-Construction Materials (2016) 169(5): 241-251. https://doi.org/10.1680/jcoma.15.00035

[14] M. Labat, M. Woloszyn, Moisture balance assessment at room-scale for four cases based on numerical simulations of heat-air-moisture transfers for a realistic occupancy scenario. J Build Perform Simul (2016) 9: 487-509. https://doi.org/10.1080/19401493.2015.1107136

[15] L. Soudani, A. Fabbri, J.-C. Morel, M. Woloszyn, P.-A. Chabriac, H. Wong, A.-C. Grillet, Assessment of the validity of some common assumptions in hygrothermal modeling of earth based materials. Energy Build (2016) 116:498-511. https://doi.org/10.1016/j.enbuild.2016.01.025

[16] F. McGregor, A. Fabbri, J. Ferreira, T. Simoes, P. Faria, J.-C. Morel, Procedure to determine the impact of the surface film resistance on the hygric properties of composite clay/fibre plasters. Mater Struct (2017) 50:193. https://doi.org/10.1617/s11527-017-1061-3

[17] O. Vololonirina, B. Perrin, Inquiries into the measurement of vapour permeability of permeable materials. Constr Build Mater (2016) 102: 338-348. https://doi.org/10.1016/i.conbuildmat.2015.10.126

[18] M. Hall, R. Lindsay, M. Krayenhoff, Modern Earth Buildings 1st Edition Materials, Engineering, Constructions and Applications (2012) https://doi.org/10.1533/9780857096166

[19] J.-C. Morel, A. Pkla, P. Walker, Compressive strength testing of compressed earth blocks. Constr Build Mater (2007) 21: 303-309. 
https://doi.org/10.1016/j.conbuildmat.2005.08.021

[20] J.-E. Aubert, A. Fabbri, J.-C. Morel, P. Maillard, A soil block with a compressive strength higher than $50 \mathrm{MPa}$ ! Constr Build Mater (2013) 47: 366-369. https://doi.org/10.1016/j.conbuildmat.2013.05.068

[21] Q.B. Bui, S. Hans, J.-C. Morel, A.P. Do, First exploratory study on dynamic characteristics of rammed earth buildings. Eng Struct (2011) 33(12): 3690-3695. https://doi.org/10.1016/j.engstruct.2011.08.004

[22] K.S. Nanjunda Rao, M. Anitha, B.V. Venkatarama Reddy, Dynamic behavior of scaled Cement Stabilized Rammed Earth building models. Rammed Earth Construction Cutting-Edge Research on Traditional and Modern Rammed Earth, D. Ciancio, C. Beckett (Eds), 2015

[23] MM. Rafi, SH. Lodi, Comparison of dynamic behaviours of retrofitted and unretrofitted cob material walls. Bull Earthq Eng (2017) 15:38553869. https://doi.org/10.1007/s10518-017-0117-7

[24] Q.B. Bui, A. Limam, T.T. Bui, Dynamic discrete element modelling for seismic assessment of rammed earth walls. Eng Struct (2018) 175: 690-699. https://doi.org/10.1016/i.engstruct.2018.08.084

[25] T.L. Bui, T.T. Bui, Q.B. Bui, X.H. Nguyen, A. Limam, Out-of-plane Behavior of Rammed Earth Walls under Seismic Loading: Finite Element Simulation. Struct (2020) 24: 191-208. https://doi.org/10.1016/i.istruc.2020.01.009

[26] R. El-Nabouch, Q.B. Bui, O. Plé, P. Perrotin, Assessing the in-plane seismic performance of rammed earth walls by using horizontal loading tests. Eng Struct (2017) 145: 153-161. https://doi.org/10.1016/i.engstruct.2017.05.027

[27] L. Miccoli, A. Drougkas, U. Müller, In-plane behaviour of rammed earth under cyclic loading: Experimental testing and finite element modelling. Eng Struct (2016) 125: 144-152. https://doi.org/10.1016/j.engstruct.2016.07.010

[28] E. Bernat-Maso, L. Gil, C. Escrig, Textile-reinforced rammed earth: Experimental characterisation of flexural strength and toughness. Constr Build Mater (2016) 106(4): 70-79. https://doi.org/10.1016/j.conbuildmat.2015.12.139

[29] A. Bove, G. Misseri, L. Rovero, U. Tonietti, Experimental and numerical analyses on the antiseismic effectiveness of fiber textile for earthen buildings. J Mater Env Sci (2016) 7(10) : 3548-3557

[30] A. Charleson, M. Blondet, Seismic reinforcement for adobe houses with straps from used car tires. Earthquake Spectra (2012) 28(2): $511-$ 530. https://doi.org/10.1193/1.4000014

[31] Q.B. Bui, T.T. Bui, R. El-Nabouch, D.K. Thai, Vertical Rods as a Seismic Reinforcement Technique for Rammed Earth Walls: An Assessment. Advances Civ Eng (2019). https://doi.org/10.1155/2019/1285937

[32] H. Hamilton, J. McBride, J. Grill, Cyclic Testing of Rammed-Earth Walls Containing Post-tensioned Reinforcement. Earthquake Spectra (2006) 22(4): 937-959. https://doi.org/10.1193/1.2358382

[33] S.S. Mahini. Smeared crack material modelling for the nonlinear analysis of CFRP-strengthened historical brick vaults with adobe piers. Constr Build Mater 7(2015) 4:201-218. https://doi.org/10.1016/j.conbuildmat.2014.10.033

[34] Y. Wang, M. Wang, K. Liu, W. Pan, X. Yang, Shaking table tests on seismic retrofitting of rammed-earth structures. Bull Earthq Eng (2016) 15(3):1037-1055. https://doi.org/10.1007/s10518-016-9996-2

[35] F. Vieux-Champagne, Y. Sieffert, S. Grange, C. Belinga Nko'ol, E. Bertrand, J.C. Duccini, C. Faye, L. Daudeville, Experimental Analysis of a Shake Table Test of Timber-Framed Structures with Stone and Earth Infill. Earthquake Spectra (2017) 33(3):1075-1100. https://doi.org/10.1193/010516eqs002m

[36] CEN (European Committee for Standardization) (2004) Eurocode 8: Design of structures for earthquake resistance, Part 1: General rules, seismic actions and rules for buildings. EN 1998-1:2004. Brussels, Belgium.

[37] A.W. Bruno, C. Perlot, J. Mendes, D. Gallipoli, A microstructural insight into the hygro-mechanical behaviour of a stabilised hypercompacted earth. Mater Struct (2018) 51 (1) : 32 https://doi.org/10.1617/s11527-018-1160-9

[38] J.-E. Aubert, M. Gasc-Barbier, Hardening of clayey soil blocks during freezing and thawing cycles. Appl Clay Sci (2012) 65 : 1-5. https://doi.org/10.1016/i.clay.2012.04.014

[39] M.I. Gomes, T.D. Gonçalves, P. Faria, Hydric behavior of earth materials and the effects of their stabilization with cement or lime: study on repair mortars for historical rammed earth structures. J Mater Civ Eng (2016) 28(7): 1-11. https://doi.org/10.1061/(ASCE)MT.1943-5533.0001536

[40] G. Cultrone, C. Rodriguez-Navarro, E. Sebastian, O. Cazalla, M.J. De La Torre, Carbonate and silicate phase reactions during ceramic firing. Eur J Mineralogy (2001) 13(3): 621-634. https://doi.org/10.1127/0935-1221/2001/0013-0621
[41] M.J. Melo, S. Bracci, M. Camaiti, O. Chiantore, F. Piacenti, Photodegradation of acrylic resins used in the conservation of stone. Polymer Degradation and Stability (1999) 66(1): 23-30. https://doi.org/10.1016/S0141-3910(99)00048-8

[42] A.H. Meek, C.T.S Beckett, M. Elchalakani, Reinforcement corrosion in cement- and alternatively-stabilised rammed earth materials. Constr Build Mater (2021) 274. https://doi.org/10.1016/j.conbuildmat.2020.122045

[43] A. Fabbri, J.-C. Morel, D. Gallipoli, Assessing the performance of earth building materials: a review of recent developments, RILEM Tech Lett (2018) 30: 46-58. https://doi.org/10.21809/rilemtechlett.2018.71

[44] Q.B. Bui, J.-C. Morel, B.V. Reddy, W. Ghayad, Durability of rammed earth walls exposed for 20 years to natural weathering. Build Environ (2009) 44(5): 912-919. https://doi.org/10.1016/i.buildenv.2008.07.001

[45] H. Schroeder, The New DIN Standards in Earth Building - The Current Situation in Germany. J Civ Eng Archit (2018) 12(2): 113-120. https://doi.org/10.17265/1934-7359/2018.02.005

[46] G. Giuffrida, R. Caponetto, M. Cuomo, An overview on contemporary rammed earth buildings: technological advances in production, construction and material characterization. IOP Conf. Ser.: Earth Environ. Sci., Milan (Italy), 2019. https://doi.org/10.1088/1755-1315/296/1/012018

[47] K. Dick, T. Krahn, Preparing regulatory challenges and opportunities for small to medium residential scale stabilized rammed earth buildings in Canada. Rammed Earth Construction, D. Ciancio, C. Beckett (Eds.), 2015, 93-96.

[48] MOPT. Bases para el diseno y construccion con tapial. Madrid: Centro de Publicationes Secretaria General Tecnica Ministerio de Obras Publicas y Transportes; 1992

[49] P. Müller, L. Miccoli, P. Fontana, C. Ziegert, Development of partial safety factors for earth block masonry. Mater Struct (2017) 50(1):31. https://doi.org/10.1617/s11527-016-0902-9

[50] D. Easton, T. Easton, Modern rammed earth construction techniques. Modern Earth Buildings, Elsevier, 2012, 364-384. https://doi.org/10.1533/9780857096166.3.364

[51] L. Ben-Alon, V. Loftness, K.A. Harries, E.C. Hameen, M. Bridges, Integrating Earthen Building Materials and Methods Into Mainstream Construction. J Green Build (2020) 15 : 87-106. https://doi.org/10.3992/1943-4618.15.1.87

[52] H. Van Damme, H. Houben, Earth concrete. Stabilization revisited. Cem Concr Res (2018) 114: 90-102. https://doi.org/10.1016/j.cemconres.2017.02.035

[53] A. Laborel-Préneron, J-E. Aubert, C. Magniont, C. Tribout, A. Bertron, Plant aggregates and fibers in earth construction materials: A review. Constr Build Mater (2016) 111: 719-734. https://doi.org/10.1016/j.conbuildmat.2016.02.119

[54] A. Cuccurullo, D. Gallipoli, A.W. Bruno, C. Augade, P. Hughes, C. La Borderie, Earth stabilisation via carbonate precipitation by plantderived urease for building applications. Geomechanics for Energy and the Environment (2020) In press, available online https://doi.org/10.1016/i.gete.2020.100230

[55] A.W. Bruno, D. Gallipoli, C. Perlot, J. Mendes, Effect of stabilisation on mechanical properties, moisture buffering and water durability of hypercompacted earth. Constr Build Mater (2017) 149 : 733-740. https://doi.org/10.1016/j.conbuildmat.2017.05.182

[56] J.-C. Morel, R. Charef, E. Hamard, A. Fabbri, C. Beckett, Q.B. Bui, Earth as construction material in the circular economy context: practitioner perspectives on barriers to overcome. Phil Trans R Soc B (2021) 376. https://doi.org/10.1098/rstb.2020.0182

[57] R. Charef, E. Ganjian, S. Emmitt, Socio-economic and environmental barriers for a holistic asset lifecycle approach to achieve circular economy: A pattern-matching method. Technol Forecast Soc Chang (2021) 170. https://doi.org/10.1016/j.techfore.2021.120798

[58] R. Charef, W. Lu, Factor dynamics to facilitate circular economy adoption in construction. J Clean Prod (2021) 319. https://doi.org/10.1016/j.jclepro.2021.128639

[59] P. Smith, S.D. Keesstra, W.L. Silver, T.K. Adhya, G.B. De Deyn, L.G. Carvalheiro, D.L. Giltrap, P. Renforth, K. Cheng, B. Sarkar, P.M. Saco, K. Scow, J. Smith, J.-C. Morel, S. Thiele-Bruhn, R. Lal, P. McElwee, Soilderived Nature's Contributions to People and their contribution to the UN Sustainable Development Goals, Phil Trans R Soc B (2021). https://doi.org/10.1098/rstb.2020.0185

[60] S. Jörchel, Modern Earth Building - the Current State of Earth Building from a German Perspective. IOP Conf Ser: Earth Environ Sci, 2019, 290, 012018. https://doi.org/10.1088/1755-1315/290/1/012018 